\title{
Biological Characteristics and Medical Treatment of Breast Cancer in Young Women-A Featured Population: Results from the NORA Study
}

\author{
P. Pronzato, ${ }^{1}$ G. Mustacchi, ${ }^{2}$ A. De Matteis, ${ }^{3}$ F. Di Costanzo, ${ }^{4}$ E. Rulli, ${ }^{5}$ \\ I. Floriani, ${ }^{5}$ and M. E. Cazzaniga ${ }^{6}$ \\ ${ }^{1}$ Oncologia Medica, IST, Genova 16010, Italy \\ ${ }^{2}$ Medical Oncology Department, University of Trieste, Trieste 34010, Italy \\ ${ }^{3}$ Medical Oncology C, National Cancer Institute, G. Pascale Foundation, Napoli 80010, Italy \\ ${ }^{4}$ Medical Oncology, Careggi University Hospital, Firenze 50012, Italy \\ ${ }^{5}$ Oncology Department, Mario Negri Institute for Pharmacological Research, Milano 20100, Italy \\ ${ }^{6}$ Medical Oncology, San Gerardo Hospital, Az Osp San Gerardo, Via Pergolesi 33, 20052 Monza, Italy
}

Correspondence should be addressed to M. E. Cazzaniga, oncologia@tin.it

Received 24 May 2010; Accepted 16 August 2010

Academic Editor: Lucia Del Mastro

Copyright (c) 2011 P. Pronzato et al. This is an open access article distributed under the Creative Commons Attribution License, which permits unrestricted use, distribution, and reproduction in any medium, provided the original work is properly cited.

Background. The present paper described the biological characteristics and clinical behavior of young women in the cohort NORA study Patients and Methods. From 2000-2002, patients $(N>3500)$ were enrolled at 77 Italian hospitals. Women aged $\leq 50$ years $(N=1013)$ were stratified into age groups $(\leq 35,36-40,41-45$, and $46-50$ years). The relationship between age and patient characteristics, cancer presentation, and treatment was analyzed. Results. Younger women more frequently had tumors with ER/PgR-negative $\left(\chi^{2}=7.07 ; P=.008\right)$, HER2 amplification $\left(\chi^{2}=5.76 ; P=.01\right)$, and high $(\geq 10 \%)$ Ki67 labelling index $\left(\chi^{2}=9.53\right.$; $P=.002)$. Positive nodal status, large tumors, and elevated Ki67 all associated with the choice for chemotherapy followed by endocrine therapy in hormone receptor-positive patients $(P<.0001)$. At univariate analysis, ER-ve status, chemotherapy and age resulted as the only statistically significant variables ( $\mathrm{HR}=2.02, P=.004$, and $>40$ versus $\leq 40, P<.0001$, resp.). At multivariate analysis, after adjustment for significant clinical and pathological factors, age remains a significant prognostic variable $(\mathrm{HR}=0.93$, $P=.0021)$. Conclusion. This cohort study suggests that age per sè is an important prognostic factor. The restricted role of early diagnosis and the aggressive behavior of cancer in this population make necessary the application of targeted medical strategies crucial.

\section{Introduction}

The incidence of breast cancer increases with age but is not infrequent in women younger than age 40 years; approximately $2 \%$ of women are younger than 35 years when breast cancer is diagnosed [1]. Breast cancer has been reported to be more aggressive and to be associated with a more unfavorable prognosis in younger patients. Whereas management problems in older patients tend to be related to health and social aspects of the aging women, in young people, other factors, such as familial and reproductive problems, have to be considered. Trials of premenopausal or young breast cancer patients have been conducted or are ongoing, but data from clinical practice are lacking.
The principal aim of the NORA (National Oncological Research observatory on Adjuvant therapy in breast cancer) study was to describe treatment strategies and reasons for their selection in a population of breast cancer patients radically treated after surgery. This paper presents data concerning the biological characteristics of breast cancer and adjuvant treatment strategies in women $\leq 50$ years, stratified according to age group.

\section{Patients and Methods}

The NORA survey was a multicenter, longitudinal, observational cohort study involving oncology centers at both academic and nonacademic institutions, which were distributed 
throughout Italy. Each center was required to register data on the first 10 consecutive patients treated in the years 2000, 2001, and 2002 (retrospective cohort) and on the first 20 consecutive patients who reached the oncology unit in 2003 (prospective cohort), for a total of 50 patients per center. These criteria were selected with the aim of maximizing enrollment while shortening the time needed to obtain an adequate followup period. Inclusion criteria included: first diagnosis of invasive breast cancer and absence of metastatic disease. Women affected by in situ carcinoma alone or who had undergone surgery with palliative intent (macroscopic residual disease) were considered ineligible. Concomitant participation in a clinical study did not qualify as an exclusion criterion as long as the proportion of these patients remained below $20 \%$ and $40 \%$ in the retrospective and prospective cohorts, respectively. Patients enrolled in a clinical trial who exceeded these rates were not considered for the analysis, but only registered. Data on demographic characteristics, familial and pathological history, diagnostic methods, surgery, pathological features, and adjuvant treatments were collected. In order to collect data on changes in adjuvant treatment, toxicity, and cancer-related events, all patients were followed up every 6 months for a minimum of 4 to a maximum of 8 years.

The study complied with the requirements of Italian law regarding observational studies. The nature and purposes of the survey were explained in detail to all potential participants, and their consent to data handling according to Italian privacy regulations was obtained. Assuming involvement of approximately 70 centers with a minimum recruitment of 50 patients, investigators planned to enroll approximately 3500 women. This number allows an estimate of the distribution of adjuvant strategies with a 95\% confidence interval (CI) range of no more than $3 \%$.

This paper presents data on the biological characteristics and medical treatment of women $\leq 50$ years old. To better study the influence of age on patterns of care and the distribution of selected factors related to patient characteristics, we identified four groups: $\leq 35,36-40,41-45$, and $46-50$ years. The characteristics of selected factors across age groups were described by relative and absolute frequencies. We were not able to detail menopausal status, mainly because data in the retrospective cohort were lacking or largely incomplete. Analyses were performed using the Mantel-Haenszel test for trend and the chi-square test for heterogeneity. Cox's model was applied for univariate analysis. Unless otherwise specified, all tests were within one degree of freedom.

\section{Results}

A total of 3532 breast cancer patients were enrolled by 71 Italian centers. Seventeen patients $(0.5 \%)$ were subsequently excluded because of synchronous tumors, leaving 3515 evaluable patients. Academic institutions comprised 21.2\% of the centers; $42.3 \%$ were located in northern Italy, $28.2 \%$ in central Italy, and $29.6 \%$ in southern Italy and the islands. Therefore, the institutions were well distributed and representative of the country.
TABle 1: Age distribution at the time of study entry.

\begin{tabular}{lcc}
\hline Age (years) & $N$ & $\%$ \\
\hline$\leq 35$ & 78 & 7.7 \\
$35-40$ & 163 & 16.1 \\
$41-45$ & 308 & 30.4 \\
$46-50$ & 463 & 45.8
\end{tabular}

Median age: 44.4 (minimum-maximum: 24-50).

Baseline characteristics and pathological features of the entire patient population have been reported previously [2]. Briefly, the median age of the patients in the whole population was 58 years (range 25-92); almost all of them had a good ECOG PS (0-1: 98.2\%) and were postmenopausal when breast cancer was diagnosed (72.3\%). Approximately onethird of the patients had a positive history of cardiovascular $(24.1 \%)$ or gynaecological $(13.2 \%)$ comorbidities. At the time of study entry, $1013(28.8 \%)$ patients were $\leq 50$ years (Table 1 ), and most of them were not menopausal $(79.8 \%)$. The median age was 44.4 years (minimum-maximum value: 24-50). Comorbidities are infrequent in the majority of the patients $<35$ years $(18.2 \%)$ and tend to be more present with increasing age $\left(\chi^{2}=16.87 ; P<.0001\right)$, particularly skeletal diseases.

Breast cancer was detected by self-examination in the majority of patients $\leq 35$ years $(80 \%)$ and by periodic screening programs in those $40-45$ years $(23.5 \%)$ and $45-50$ years $(23.8 \%)$, which is similar to that observed in the whole population (Table 2).

Conservative surgery was performed in $66.4 \%$ of the cases, without any significant difference across age groups $\left(\chi^{2}=1.35 ; P=.24\right)$. In the $\leq 35$ age group, mastectomy was performed in $34.6 \%$ of the cases, despite the fact that small tumors $(<2 \mathrm{~cm})$ were found in $57.7 \%$ of the patients. Sentinel node technique was used together with conservative surgery in $14.1 \%$ of the cases, without any difference according to age group $\left(\chi^{2}=0.02 ; P=.87\right)$.

Histologic characteristics were similar among all subgroups, except for the lobular subtype, which tended to be more frequent among women older than 35 years and was rare in women $\leq 35$ years $(10.5 \%$ versus $2.6 \%$, resp.).

3.1. pTN Stage and Biological Characteristics. T stage and nodal involvement (TN) as well as the chief biological characteristics are reported in Table 3. The distribution of TN stage did not differ according to age group $\left(\chi^{2}=2.18 ; P=\right.$ $.13)$; on the contrary, hormone receptor status, human epidermal growth factor receptor 2 (HER2) amplification, and elevated Ki67 labelling index showed statistically significant correlations with age (Tables 4 and 5), being more frequently present in the group younger than 35 years. Thus, the tumours of younger women were more frequently estrogen receptor $(\mathrm{ER}) /$ progesterone receptor $(\mathrm{PgR})$-negative $\left(\chi^{2}=\right.$ 7.07; $P=.008)$, HER2 amplified $\left(\chi^{2}=5.76 ; P=.01\right)$, and with high $(\geq 10 \%)$ Ki67 labelling index $\left(\chi^{2}=9.53\right.$; $P=.002)$. 
TABLE 2: Diagnosis of breast cancer- $n(\%)$.

\begin{tabular}{|c|c|c|c|c|c|}
\hline & $\leq 35(\%)$ & $36-40(\%)$ & $41-45(\%)$ & $46-50(\%)$ & Total (\%) \\
\hline Self-breast examination & $56(80.0)$ & $92(66.7)$ & $151(56.3)$ & $194(49.6)$ & $493(56.9)$ \\
\hline Periodical screening & $3(4.3)$ & $9(66.7)$ & $63(23.5)$ & $93(23.8)$ & $168(19.4)$ \\
\hline Occasional finding & $11(15.7)$ & $37(26.8)$ & $53(19.8)$ & $101(25.8)$ & $202(23.3)$ \\
\hline Other & & & & & 4 \\
\hline Missing & & & & & 145 \\
\hline
\end{tabular}

$\chi^{2}=45.53 ; P<.001$.

TABLE 3: TN stage according to age groups- $n(\%)$.

\begin{tabular}{|c|c|c|c|c|c|}
\hline & $\leq 35(\%)$ & $36-40(\%)$ & $41-45(\%)$ & $46-50(\%)$ & Total (\%) \\
\hline$P \mathrm{~T}_{1}^{*}$ & $45(57.7)$ & $88(54.7)$ & $194(63.0)$ & $294(63.8)$ & $621(61.6)$ \\
\hline$P \mathrm{~T}_{2}$ & $30(38.5)$ & $63(39.1)$ & $103(33.4)$ & $147(31.9)$ & $343(34.0)$ \\
\hline$P \mathrm{~T}_{3}$ & $2(2.6)$ & $10(6.2)$ & $5(1.6)$ & $12(2.6)$ & 29 (2.9) \\
\hline $\mathrm{PT}_{4}$ & $1(1.3)$ & $0(0.0)$ & $6(2.0)$ & $8(7.0)$ & $15(1.5)$ \\
\hline$P \mathrm{~N}_{0}^{* *}$ & $44(57.9)$ & $84(52.5)$ & $154(51.9)$ & $269(59.7)$ & $551(54.4)$ \\
\hline$P \mathrm{~N}_{1-3}$ & $21(27.6)$ & $38(23.8)$ & $89(29.1)$ & $126(27.9)$ & $274(27.8)$ \\
\hline$P \mathrm{~N}_{4-10}$ & $5(6.6)$ & $25(15.6)$ & $35(11.8)$ & $35(7.8)$ & $100(10.2)$ \\
\hline$P \mathrm{~N}_{>10}$ & $6(7.9)$ & $13(8.1)$ & $19(6.4)$ & $21(4.7)$ & $59(6.0)$ \\
\hline Missing & & & & & 28 \\
\hline
\end{tabular}

$* \chi^{2}=2.18 ; P=.13$.

$* * \chi^{2}=3.06 ; P=.08$.

3.2. Adjuvant Medical Treatment. The choice of adjuvant medical treatment also correlated with age. Endocrine therapy alone was more frequently administered to women older than 35 years ( $\leq 35$ : $0 \%$; 36-40: 7.4\%; 41-45: 14.9\%; 45-50: $20.1 \%$ ) whereas younger women were more likely to receive chemotherapy alone or chemotherapy followed by endocrine therapy $\left(\chi^{2}=35.43 ; P<.0001\right)$. If we analyse the choice of adjuvant therapy according to the hormone status (Table 6), we observe that almost all patients who were $\mathrm{ER}+/ \mathrm{PgR}+$ received endocrine therapy alone or chemofollowed by endocrine therapy, independently of age, even if older patients were most likely to be treated with a treatment containing hormones, in comparison to younger ones. This finding is consistent with the more frequent presence of hormone receptors in older women $\left(\chi^{2}=699.89 ; P<.0001\right)$.

No differences were observed in the type of adjuvant chemotherapy $\left(\chi^{2}=12.09 ; P=.2\right)$. Anthracycline-based chemotherapy was the preferred choice in the whole group $(65.2 \%)$ as well as in all subgroups of patients (Table 7).

Endocrine therapy alone was administered in 151 patients. Eighty-one patients received tamoxifen and 70 a luteinizing hormone-releasing hormone (LHRH) analogue with or without tamoxifen. Of 636 patients who received chemotherapy followed by endocrine therapy, an anthracycline-based regimen was chosen in 352 (55.8\%); cyclophosphamide, methotrexate, and fluorouracil in 233 (37\%), and a taxane-based therapy in 39 (6.2\%).

The choice between endocrine therapy and chemotherapy was mainly based on the patient's hormone receptor status. Endocrine therapy was widely used in hormone receptor-positive patients, while chemotherapy was preferred in patients who were hormone receptor-negative $\left(\chi^{2}=\right.$ 699.89; $P<.0001)$.

In the hormone receptor-positive population, the preference for chemotherapy followed by endocrine therapy was strongly influenced by nodal status $(\mathrm{N}+$ versus $\mathrm{N}-:$ : 69.6\% versus $\left.97.9 \% ; \chi^{2}=102.20 ; P<.0001\right)$, $\mathrm{T}$ stage $\left(\mathrm{T}_{1}\right.$ versus T>1: $73.8 \%$ versus $\left.95 \% ; \chi^{2}=56.15 ; P<.0001\right)$, and elevated Ki67 $\left(\leq 10 \%\right.$ versus $\left.>10 \% ; \chi^{2}=15.43 ; P<.0001\right)$. The lack of expression of $\mathrm{PgR}$ did not seem to influence the choice between endocrine therapy alone or chemotherapy followed by endocrine therapy $(P=.6)$, but no conclusion could be drawn regarding the influence of HER2 status because of the high percentage of missing values. The menopausal status did not have any relevance on the choice between chemotherapy or endocrine therapy $\left(\chi^{2}=0.68\right.$; $P=.71)$.

There was a statistically significant difference among age groups in terms of DFS (Figure 1(a)). The worse prognosis was observed in those aged 35-40 $\left(\chi^{2}=27.69 ; P<\right.$ .0001). There were no significant differences between age groups in terms of overall survival (OS); however, OS was statistically better in younger patients compared with the total population studied (Figure 1(b)).

At univariate analysis, ER-ve status $(\mathrm{HR}=2.02, P=$ $.004)$, choice for chemotherapy ( $\mathrm{HR}=4.45, P=.019)$, and age $(<40$ versus $\leq 40, \mathrm{HR}=0.34, P<.0001)$ were independent variables all associated with worse DFS.

At multivariate analysis, when adjusted for the clinical and biological factors significant at univariate analysis, age remains a statistically significant independent variable $(\mathrm{HR}=0.39, P<.0001)$ for worse DFS. 
TABLE 4: Human epidermal growth factor receptor 2 (HER2)-neu and labelling index according to age. Younger age correlates with HER2neu positive status and high Ki67.

\begin{tabular}{|c|c|c|c|c|c|}
\hline HER2 status & $\leq 35(\%)$ & $36-40(\%)$ & $41-45(\%)$ & $46-50(\%)$ & Total (\%) \\
\hline HER2 0 & $14(35.9)$ & $31(34.4)$ & $52(36.9)$ & $100(44.6)$ & $197(39.9)$ \\
\hline HER2 1+ & $6(15.4)$ & $18(20.0)$ & $28(19.9)$ & $42(18.8)$ & $94(19.0)$ \\
\hline HER2 $2+$ & $6(15.4)$ & $16(17.8)$ & $28(19.9)$ & $45(20.1)$ & $95(19.2)$ \\
\hline HER2 3+ & $13(33.3)$ & $25(27.8)$ & $33(23.4)$ & $37(16.5)$ & $108(21.9)$ \\
\hline Missing & & & & & 518 \\
\hline \multicolumn{6}{|c|}{ Labelling index-Ki 67} \\
\hline Ki67 $\leq 10 \%$ & $5(8.1)$ & $28(23.1)$ & $56(24.2)$ & $99(27.3)$ & $188(24.2)$ \\
\hline Ki67 >10\%* & 57 (91.9) & $93(76.9)$ & $175(75.8)$ & $264(72.7)$ & $589(75.8)$ \\
\hline Missing & & & & & 235 \\
\hline
\end{tabular}

TABLE 5: Hormone receptor status stratified by age group. Younger age more frequently correlates with lack of hormone receptors.

\begin{tabular}{lcccccc}
\hline \multirow{2}{*}{ HR status } & \multicolumn{2}{c}{ PgR+ ${ }^{2}$} & \multicolumn{2}{c}{ PgR- } & \multicolumn{2}{c}{ Total } \\
& $N$ & $\%$ & $N$ & $\%$ & $N$ & $\%$ \\
\hline$\leq 35$ years & & & & & & \\
ER+ & 43 & 58.1 & 6 & 8.1 & 49 & 66.2 \\
ER- & 6 & 8.1 & 19 & 25.7 & 25 & 33.8 \\
Total & 49 & 66.2 & 25 & 33.8 & 74 & 100.0 \\
\hline $36-40$ years & & & & & & \\
ER+ & 106 & 66.3 & 18 & 11.3 & 124 & 77.5 \\
ER- & 5 & 3.1 & 31 & 19.4 & 36 & 22.5 \\
Total & 111 & 69.4 & 49 & 30.6 & 160 & 100.0 \\
\hline $41-45$ years & & & & & & \\
ER+ & 199 & 66.1 & 26 & 8.6 & 225 & 74.8 \\
ER- & 15 & 5.0 & 61 & 20.3 & 76 & 25.2 \\
Total & 214 & 71.1 & 87 & 28.9 & 301 & 100.0 \\
\hline $46-50$ years & & & & & & \\
ER+ & 328 & 72.6 & 34 & 7.5 & 362 & 80.1 \\
ER- & 19 & 4.2 & 71 & 15.7 & 90 & 19.9 \\
Total & 347 & 76.8 & 105 & 23.2 & 452 & 100.0 \\
\hline
\end{tabular}

$\chi^{2}=7.07 ; P=.0078$.

ER: estrogen receptor. HR: hormone receptor. PgR: progesterone receptor.

\section{Discussion}

The population analyzed in this paper consisted of 1014 women $\leq 50$ years of age. As expected, the majority of the patients did not have the comorbidities observed in older women [3] that can limit the choice of treatment. Yet even among women aged 41-50, the risk of cardiovascular, skeletal, and gynecological disease may be important enough to have an impact on treatment selection.

At the time patients entered the cohort study, evidence did not support a screening mammogram in these women. Nevertheless, $34.3 \%$ of the patients in this age group had their breast cancer diagnosed by a periodic screening test. This could be interpreted as a sporadic finding. Debate
TABle 6: Adjuvant treatment according to hormone receptor status and age. Endocrine therapy is more frequently administered in $\mathrm{HR}+$ patients, independently of age $\left(\chi^{2}=699.89 ; 6 \mathrm{df} ; P<.0001\right)$.

\begin{tabular}{cccccccc}
\hline & & \multicolumn{2}{c}{ HT } & \multicolumn{2}{c}{ CHT } & \multicolumn{2}{c}{ CHT-HT } \\
& & $N$ & $\%$ & $N$ & $\%$ & $N$ & $\%$ \\
\hline \multirow{5}{*}{ ER+/PgR+ } & $36-40$ & 10 & 9.5 & 8 & 7.6 & 87 & 82.9 \\
& $41-45$ & 40 & 20.4 & 6 & 3.1 & 150 & 76.5 \\
& $46-50$ & 78 & 23.9 & 5 & 1.5 & 243 & 74.5 \\
\hline \multirow{5}{*}{ ER+/PgR- } & $\leq 35$ & 0 & 0 & 0 & 0 & 6 & 100.0 \\
& $36-40$ & 1 & 5.6 & 1 & 5.6 & 16 & 88.9 \\
& $41-45$ & 3 & 12.0 & 2 & 8.0 & 20 & 80.0 \\
& $46-50$ & 10 & 29.4 & 2 & 5.9 & 22 & 64.7 \\
\hline \multirow{5}{*}{ ER-/PgR+/PgR- } & $\leq 35$ & 0 & 0 & 2 & 33.3 & 4 & 66.7 \\
& $36-40$ & 0 & 0 & 0 & 0 & 5 & 100.0 \\
& $41-45$ & 0 & 0 & 5 & 33.3 & 10 & 66.7 \\
& $46-50$ & 3 & 15.8 & 5 & 26.3 & 11 & 57.9 \\
\hline & $36-40$ & 0 & 0 & 29 & 93.5 & 2 & 6.5 \\
& $41-45$ & 1 & 1.7 & 55 & 91.7 & 4 & 6.7 \\
& $46-50$ & 0 & 0 & 65 & 95.6 & 3 & 4.4 \\
\hline
\end{tabular}

continues about the validity of a screening mammography program for women younger than 45 years. Issues include the lower sensitivity of mammography in this subset of patients, the high rate of false-positives, and health care costs. However, the high rate of women spontaneously screened in this study could be the starting point for a more rational and cost-effective approach in this age group.

These data demonstrate that tumors that occur in very young $(<35$ years) women are characterized by a lack of hormone receptors and a high proliferation rate. Our results are similar to those described by Colleoni et al. [4]. This study was a cohort trial; thus no centralized revision of HR status or Ki67 was planned; concerning the HER2 status, we must keep in mind that these data were collected starting from 2000, when the determination was not routinely applied. With HER2-neu status being determined more 
TABLE 7: Type of adjuvant therapy in the young population and in the subgroups stratified by age.

\begin{tabular}{|c|c|c|c|c|c|}
\hline & $\leq 35(\%)$ & $36-40(\%)$ & $41-45(\%)$ & $46-50(\%)$ & Total $(\%)$ \\
\hline No therapy & $1(1.3)$ & $1(0.6)$ & $5(1.6)$ & $6(1.3)$ & $13(1.3)$ \\
\hline HT alone & 0 & $12(7.4)$ & $46(14.9)$ & $93(20.1)$ & $151(14.9)$ \\
\hline CHT alone & $23(29.5)$ & $39(23.9)$ & $70(22.7)$ & $80(17.3)$ & $212(20.9)$ \\
\hline CHT followed by HT & $54(69.2)$ & $111(68.1)$ & $187(60.7)$ & $284(61.3)$ & $636(62.8)$ \\
\hline
\end{tabular}

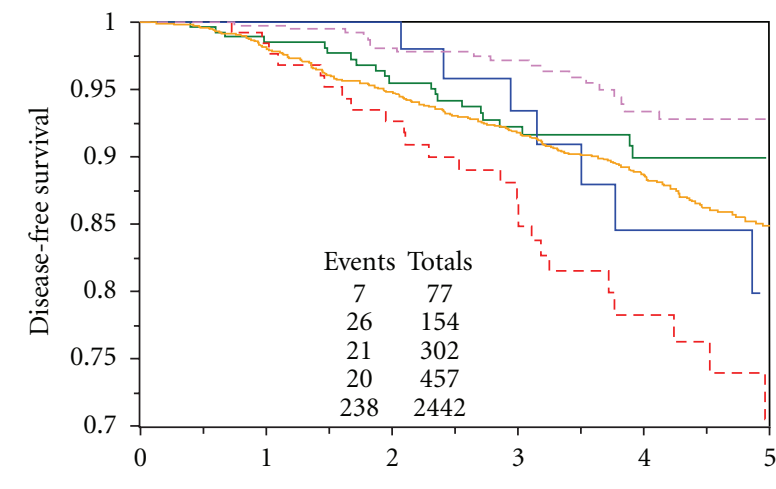

\begin{tabular}{|c|c|c|c|c|c|}
\hline \multicolumn{2}{|c|}{ Patients at risk } & \multicolumn{4}{|c|}{ (years) } \\
\hline$</=35$ & 77 & 55 & 51 & 38 & 24 \\
\hline $35-40+$ & 154 & 124 & 107 & 83 & 46 \\
\hline $40-45+$ & 302 & 249 & 218 & 169 & 89 \\
\hline \multirow{4}{*}{$\begin{array}{c}45-50+ \\
>50\end{array}$} & 457 & 380 & 341 & 259 & 168 \\
\hline & 2442 & 2061 & 1803 & 1423 & 847 \\
\hline & & $</=35$ & & \multirow{2}{*}{\multicolumn{2}{|c|}{$\begin{aligned}---- & 45-50+ \\
& >50\end{aligned}$}} \\
\hline & & $35-40+$ & & & \\
\hline
\end{tabular}

(a)
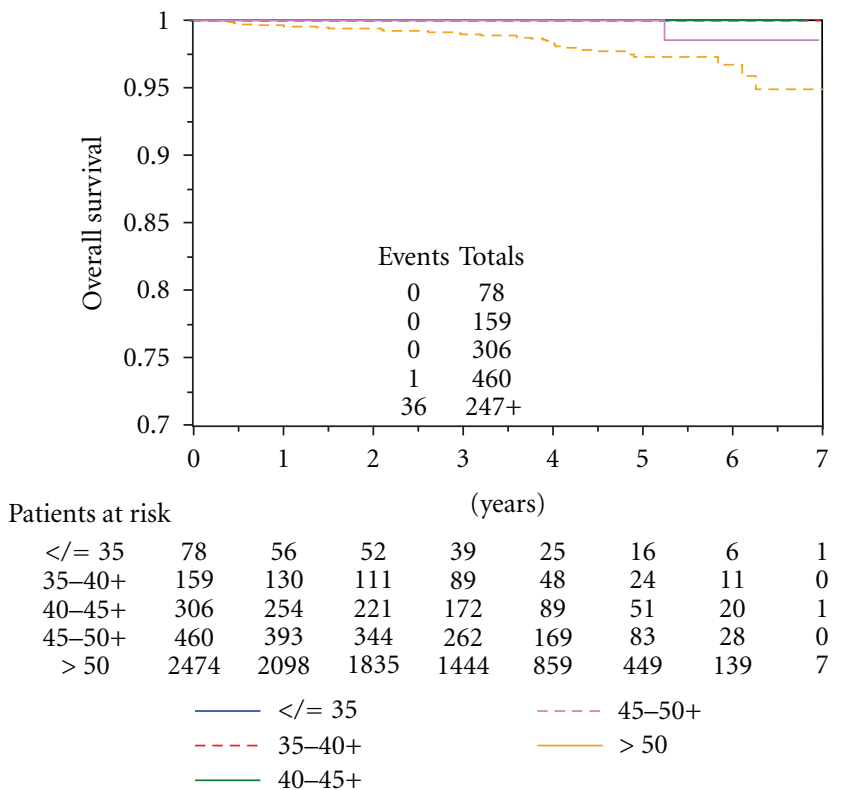

(b)

FIGURE 1: (a) Disease-free survival (DFS), and (b) overall survival (OS) according to age group.

often, very young women with breast cancer are more often found to have tumors that amplify HER2-neu in comparison with older patients $\left(\chi^{2}=5.76 ; P=.01\right)$.

In young patients, appropriate therapies may ameliorate the unfavorable prognostic features associated with age. In a study by Kroman et al. [5], young patients who did not receive adjuvant therapy had a worse prognosis than older patients with the same biological characteristics whereas for patients who received adjuvant treatment, irrespective of age, a worse prognosis was not evident.

While chemotherapy was administered to almost all women who were $\mathrm{ER} / \mathrm{PgR}-$, and endocrine therapy was given to patients with tumors that were clearly endocrineresponsive, the sequence of chemotherapy and endocrine therapy was chosen for the majority of patients with tumor expression of at least one of the two receptors. This treatment choice in patients with endocrine-sensitive breast cancer has been vigorously discussed. Some retrospective analyses have argued that the value of such a treatment sequence is limited in patients with endocrine-positive disease [6]. However, the INT 0101 trial [7], which randomized premenopausal patients to chemotherapy alone, chemotherapy plus LHRH analogs for 5 years or the same treatment with the addition of tamoxifen, demonstrated the superiority of the latter arm over the other two choices.

These results are similar to those described by Regan et al. [8], who recently analyzed the determinants for choosing chemotherapy in a population of hormone receptor-positive premenopausal patients enrolled in three different International Breast Cancer Study Group trials. Positive nodal status, higher grade tumors, and large tumors were all factors for choosing chemotherapy.

In premenopausal women, the effectiveness of chemotherapy may also be related to the induction of menopause, which has an endocrine-like effect. Studies comparing endocrine therapy with chemotherapy have not demonstrated relevant differences [9-11]. However, with the development of second- and third-generation chemotherapy regimens such as CEF, dose-dense paclitaxel, and dose-dense EC Taxol, which are more effective than standard Bonadonna CMF, and AC alone, no final conclusions should be drawn from studies that compare "first generation" chemotherapies with ovarian ablation. In this cohort study, it was quite clear that Italian oncologists preferred the use of sequential chemotherapy and endocrine therapy. However, in most cases, the choice was for a "new" anthracycline-based regimen. 


\section{Conclusions}

In young patients with breast cancer, management problems specific to this patient population could arise. In this cohort study, investigators collected data on a large series of patients aged $\leq 50$ years who were treated in clinical practice throughout Italy, outside of controlled clinical trials. The results confirm previous findings obtained by other observational trials, in particular, evidence of unfavorable biological and pathological patterns. The concept of young age as a negative prognostic factor most likely led oncologists to choose more aggressive treatments, such as chemotherapy. Because of the restricted role of early diagnosis and the aggressive behaviour of cancer in this patient population, the application of validated medical strategies is of critical importance.

\section{Conflict of Interests}

All authors must disclose any actual or potential conflict of interests including any financial, personal, or other relationships with other people or organizations within that could inappropriately influence (bias) their work.

\section{References}

[1] Surveillance, Epidemiology, and End Results (SEER) program Public-Use CD Rom (1973-1997). National Cancer Institute, DCCPS. Cancer Surveillance Research Program, Cancer Statistics Branch, April 2000.

[2] M. E. Cazzaniga, G. Mustacchi, P. Pronzato, A. De Matteis, F. Di Costanzo, and I. Floriani, "Adjuvant systemic treatment of early breast cancer: the NORA study," Annals of Oncology, vol. 17, no. 9, pp. 1386-1392, 2006.

[3] G. Mustacchi, M. E. Cazzaniga, P. Pronzato, A. De Matteis, F. Di Costanzo, and I. Floriani, "Breast cancer in elderly women: a different reality? Results from the NORA study," Annals of Oncology, vol. 18, no. 6, pp. 991-996, 2007.

[4] M. Colleoni, N. Rotmensz, C. Robertson et al., "Very young women (< 35 years) with operable breast cancer: features of disease at presentation," Annals of Oncology, vol. 13, no. 2, pp. 273-279, 2002.

[5] N. Kroman, M.-B. Jensen, J. Wohlfahrt, H. T. Mouridsen, P. K. Andersen, and M. Melbye, "Factors influencing the effect of age on prognosis in breast cancer: population based study," British Medical Journal, vol. 320, no. 7233, pp. 474-478, 2000.

[6] D. A. Berry, C. Cirrincione, I. C. Henderson et al., "Estrogenreceptor status and outcomes of modern chemotherapy for patients with node-positive breast cancer," Journal of the American Medical Association, vol. 295, no. 14, pp. 1658-1667, 2006.

[7] N. E. Davidson, A. M. O’Neill, A. M. Vukov et al., "Chemoendocrine therapy for premenopausal women with axillary lymph node-positive, steroid hormone receptorpositive breast cancer: results from INT 0101 (E5188)," Journal of Clinical Oncology, vol. 23, no. 25, pp. 5973-5982, 2005.

[8] M. M. Regan, O. Pagani, B. Walley et al., "Premenopausal endocrine-responsive early breast cancer: who receives chemotherapy?" Annals of Oncology, vol. 19, no. 7, pp. 12311241, 2008.
[9] F. Boccardo, A. Rubagotti, D. Amoroso et al., "Cyclophosphamide, methotrexate and 5Fluorouracil versus tamoxifen plus ovarian suppression as adjuvant treatment of oestrogen receptor positive pre/peri-menopausal breast cancer patients: results of the Italian Breast Cancer Adjuvant Study Group 02randomized trial," Journal of Clinical Oncology, vol. 18, pp. 2718-2727, 2000.

[10] R. Jakesz, H. Hausmaninger, E. Kubista et al., "Randomized adjuvant trial of tamoxifen and goserelin versus cyclophosphamide, methotrexate, and fluorouracil: evidence for the superiority of treatment with endocrine blockade in premenopausal patients with hormone-responsive breast cancer-Austrian Breast and Colorectal Cancer Study Group Trial 5," Journal of Clinical Oncology, vol. 20, no. 24, pp. 46214627, 2002.

[11] W. Jonat, M. Kaufmann, W. Sauerbrei et al., "Goserelin versus cyclophosphamide, methotrexate and fluorouracil as adjuvant therapy in premenopausal patients with node positive breast cancer: the Zoladex Early Breast Cancer Research Association study," Journal of Clinical Oncology, vol. 20, pp. 4621-4627, 2002. 


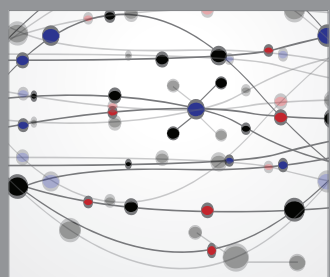

The Scientific World Journal
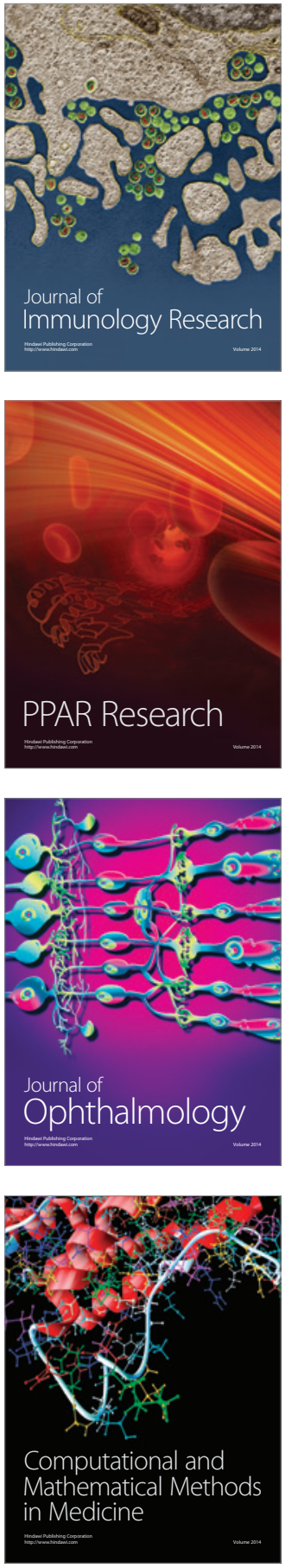

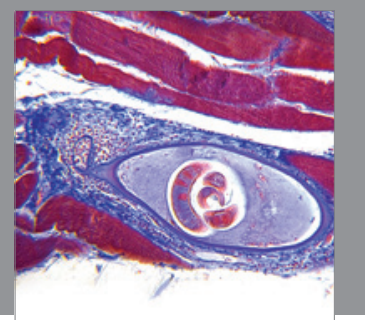

Gastroenterology

Research and Practice
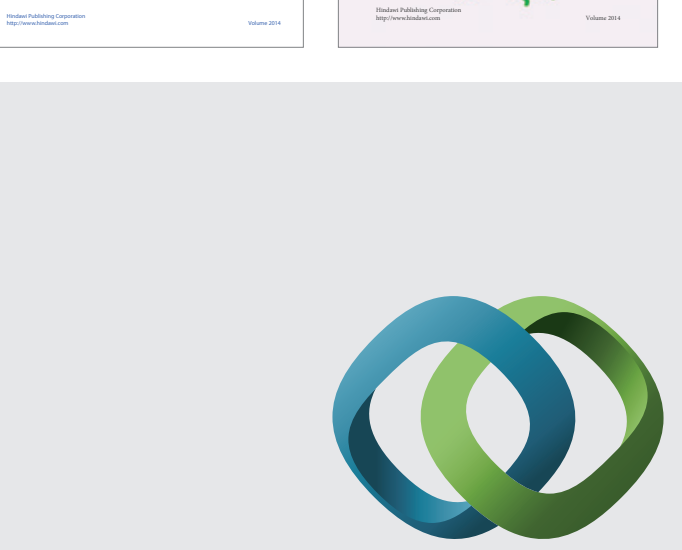

\section{Hindawi}

Submit your manuscripts at

http://www.hindawi.com
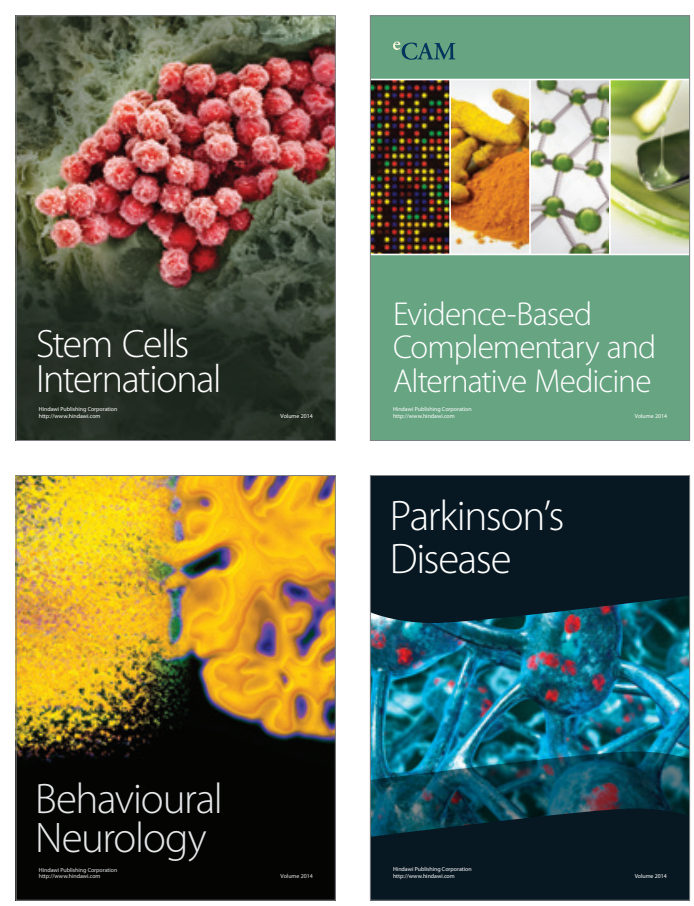

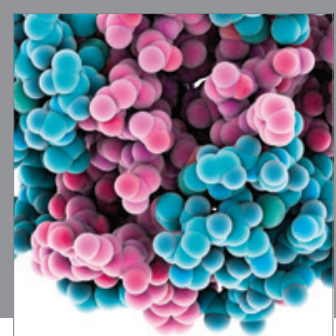

Journal of
Diabetes Research

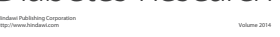

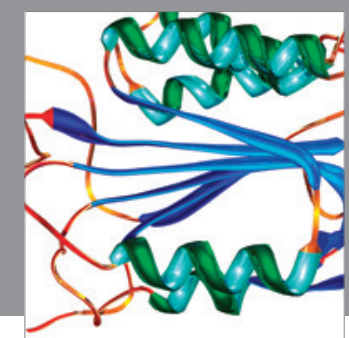

Disease Markers
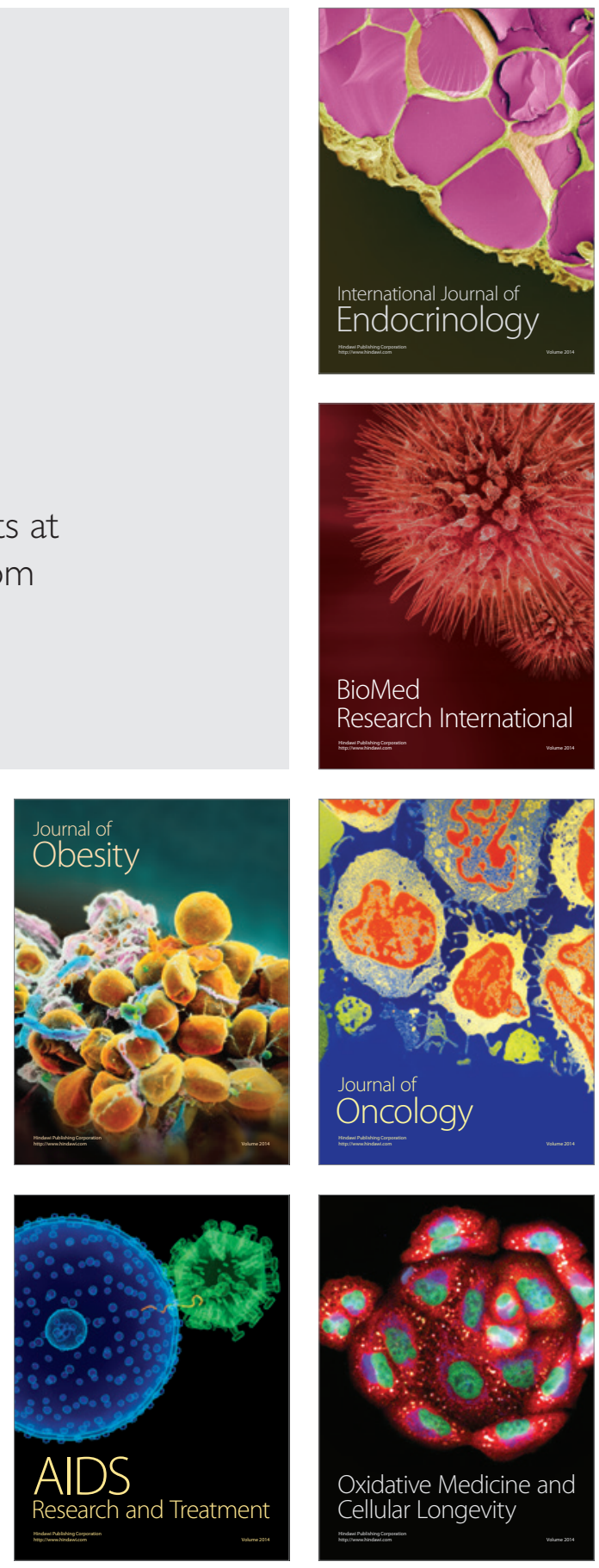